
Watson, Gordon J. 2021. Identifying conserved polychaete molecular markers of metal exposure: comparative analyses using the Alitta virens (Annelida, Lophotrochozoa) transcriptome.

(C) 2020 Elsevier B.V.

This manuscript version is made available under the CC BY-NC-ND 4.0 license https://creativecommons.org/licenses/by-nc-nd/4.0/ (cc)) EY-NC-ND

This version is available at http://nora.nerc.ac.uk/id/eprint/529242

Copyright and other rights for material on this site are retained by the rights owners. Users should read the terms and conditions of use of this material at https://nora.nerc.ac.uk/policies.html\#access.

This is an unedited manuscript accepted for publication, incorporating any revisions agreed during the peer review process. There may be differences between this and the publisher's version. You are advised to consult the publisher's version if you wish to cite from this article.

The definitive version was published in Comparative Biochemistry and Physiology, Part C: Toxicology \& Pharmacology, 240, 108913. https://doi.org/10.1016/j.cbpc.2020.108913

The definitive version is available at https://www.elsevier.com/ 


\title{
Identifying conserved polychaete molecular markers of metal exposure:Comparative analyses using the Alitta virens (Annelida, Lophotrochozoa) transcriptome
}

\author{
Amaia Green Etxabe ${ }^{a}$, Jennifer M. Pini ${ }^{b}$, Stephen Short ${ }^{c,}{ }^{,}$, Luis Cunha ${ }^{\text {d, e }}$, Peter Kille ${ }^{c}$, Gordon J. \\ Watson ${ }^{\mathrm{f}}$ \\ a UK Centre for Ecology and Hydrology, Maclean Building, Benson Lane, Wallingford, Oxfordshire OX10 8BB, UK \\ ${ }^{\mathrm{b}}$ CP-Texinfine (France), 60 Rue Duguesclin, 69006 Lyon, France \\ ${ }^{\mathrm{c}}$ Cardiff School of Biosciences, Sir Martin Evans Building, Museum Avenue, Cardiff CF10 3AT, UK \\ d University of Coimbra, Centre for Functional Ecology, Department of Life Sciences, Calçada Martim de Freitas, 3000-456 Coimbra \\ Portugal \\ e School of Applied Sciences, University of South Wales, Pontypridd, Wales CF37 4BD, UK

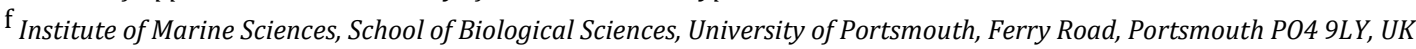 \\ *Corresponding Author: E-mail: shorts@cardiff.ac.uk
}

Keywords: Ragworm Benthic Heavy metal Haemoglobin Polychaete Pollution

\section{ABSTRACT}

Polychaetes are vital for evaluating the effects of toxic metals in marine systems, and sensitive molecular biomarkers should be integral to monitoring efforts. However, the few polychaete markers that exist are inconsistent, even within the same species, failing to identify gene expression changes in metal-exposed animals incurring clear metabolic costs. Comparing previously characterised polychaete metal-responsive genes with those of another carefully selected species could identify biomarkers applicable across polychaetes. The ragworm Alitta virens (Sars, 1835) is particularly suited for such comparisons due to its dominance of fully saline coastal areas, widespread distribution, large biomass, and its phylogenetic position relative to other polychaete 'omic' resources. A transcriptome atlas for A. virens was generated and an RNASeq-qPCR screening approach was used to characterise the response to chronic exposures of environmentally relevant concentrations of copper and zinc in controlled mesocosms. Genes presenting dramatic expression changes in A. virens were compared with known metal-responsive genes in other polychaetes to identify new possible biomarkers and assess those currently used. This revealed some current markers should probably be abandoned (e.g. Atox1), while others, such as GST- Omega, should be used with caution, as different polychaete species appear to upregulate distinct GSTOmega orthologues. In addition, the comparisons give some indication of genes that are induced by metal exposure across phylogenetically divergent polychaetes, including a suite of haemoglobin subunits and linker chains that could play conserved roles in metal-stress response. Although such newly identified markers need further characterisation, they offer alternatives to current markers that are plainly insufficient.

\section{Introduction}

Copper and zinc are highly toxic metals (King et al., 2004; Reish and Gerlinger, 1997) that are of great concern for ecotoxicological risk management (Luoma and Rainbow, 2008; Walker et al., 2005) and have been ranked first and third most toxic aquatic pollutants respectively (Johnson et al., 2017). Traditionally, $\mathrm{Cu}$ and $\mathrm{Zn}$ are seen as contamination legacies (Walker et al., 2005) and environmental regulators assumed levels would decline due to lower industrial inputs and legislation (Rainbow et al., 2011), however, recent analysis has shown that coastal sediment concentrations are stable or increasing (Watson et al., 2018). This is possibly due to inputs from the use of these metals in new applications, such as nanoparticles (Gao et al., 2013), or renewed use, such as replacing TBT in antifouling paints (Srinivasan and Swain, 2007). Crucially, these metals are predicted to be more bioavailable under predicted ocean acidification scenarios (Millero et al., 2009).

Polychaetes are found in vulnerable marine benthic communities and their role as contaminant vectors, combined with their ecological importance, means they are often used to analyse ecosystem health (Dean, 2008). Sub-lethal molecular biomarkers are used extensively to study the effects of pollutants on exposed invertebrates (Schirmer et al., 2010), yet the selection of biomarkers can be complex (Hook et al., 2014). For example, genetic adaptations are known to underpin the evolution of metal tolerance (Grant et al., 1989) and different species, or even populations of the same species, can evolve independent mechanisms for coping with pollutants (Reid et al., 2016). Metal exposed polychaete species studied at the molecular level represent a wide phylogenetic range (McQuillan et al., 2014; Neave et al., 2012; Rhee et al., 2012), leading to uncertainty about the universality of existing molecular biomarkers. Polychaetes (and marine Lophotrochozoa more generally) remain underrepresented both genomically and transcriptomically (Mehr et al., 2015). A recent study illustrates the current issues regarding the lack of metal-response markers. Analysis of Hediste diversicolor suggests while exposure at a metal contaminated site induces metabolic costs that leads to reduced weight, current gene markers failed to identify any differential gene expression (Breton and Prentiss, 2019), this is despite the 
application of biomarkers developed using H. diversicolor (McQuillan et al., 2014). However, characterising transcriptomic response to metal for a carefully selected polychaete species within the context of existing analyses (McQuillan et al., 2014; Neave et al., 2012; Rhee et al., 2007a, 2007b, 2012; Won et al., 2011) could help identify reliable and sensitive cross-species markers for monitoring diverse polychaetes.

Alitta virens (Sars, 1835) is an ideal species for ecosystem monitoring as it inhabits marine and estuarine environments in temperate regions of the northern hemisphere. It is also the dominant polychaete (and macrofaunal species more generally) in fully saline areas and has commercial importance (Kristensen and Kostka, 2005; Nielsen et al., 1995). As sediments are sinks for metals, the benthic existence of A. virens means it is continuously exposed to possible contaminants via sediment and porewater (Dean, 2008). A. virens is also phylogenetically well-placed to allow comparisons with the other polychaete transcriptomic data sets associated with metal responses; the closely related H. diversicolor and Perinereis nuntia (McQuillan et al., 2014; Santos et al., 2006; Rhee et al., 2012), and the more distantly related Ophelina (Neave et al., 2012; Rousset et al., 2007). Furthermore, toxicity experiments (Watson et al., 2018) associated with this $A$. virens transcriptomic analysis allows biomarker candidates to be anchored to measurable effects, as recommended to provide regulators with the tools to assess environmental risk (Hook et al., 2014).

Our first aim is to generate a comprehensive $A$. virens transcriptome to provide a rich resource for ecotoxicology. Our second is to use RNASeq-qPCR screening to characterise responses of $A$. virens to chronic ( $3 \& 6$ month) exposures of environmentally relevant concentrations of $\mathrm{Cu}, \mathrm{Zn}$ and $\mathrm{Cu}-\mathrm{Zn}$ using sediment-spiking. Sediment-spiking enables effects to be directly linked to test chemicals (U.S.EPA, 2005). This is particularly critical as other polychaete transcriptomic studies have compared animals from clean and contaminated sites (McQuillan et al., 2014; Neave et al., 2012; Rhee et al., 2012) where responses to a metal of interest may be obscured by acclimatisation and/or the influence of a multitude of other pollutants. Overall, we aim to identify potential biomarkers for metal-induced stress applicable across diverse polychaetes that enables comparative assessment of sensitivity and tolerance. Ultimately, this will help provide sensitive and widely applicable tools to identify and monitor vulnerable ecosystems.

\section{Materials and methods}

\subsection{Mesocosm study exposure}

Mesocosms and sample processing were as previously described (Watson et al., 2018). Briefly, sediment was spiked with seawater (control), $\mathrm{CuCl}_{2} \cdot 2 \mathrm{H}_{2} \mathrm{O}, \mathrm{ZnCl}_{2}$ or combined solutions and left for a week at $4{ }^{\circ} \mathrm{C}$ in the dark. Target bioavailable concentrations were based on UK sites (Pini, 2014), resulting in seven toxicogenomic treatments: control; low Cu; low Zn; low Cu-Zn; high Cu; high Zn; high $\mathrm{Cu}-\mathrm{Zn}$. A. virens (1-2 g) were added to each box (3 boxes per treatment per tank [3 tanks]) with each box connected to flowing seawater. Worms were fed fish pellets, $1-2 \%$ of starting biomass twice a week. One box per treatment per tank was destructively sampled in January and April 2013, sediment and porewater collected and worms depurated then weighed. Approximately $0.5 \mathrm{~cm}$ of gut tissue ( $\sim 10$ segments from head) was snap frozen in liquid nitrogen, homogenised in Tri-Reagent (Ambion, Life Technologies, Carlsbad, CA, USA) and stored at $-80^{\circ} \mathrm{C}$.

Presumed bioavailable (termed 'bioavailable' here) sediment and porewater concentrations were obtained using a BCR 3-stage sequential extraction protocol and measured by flame AAS as previously detailed (Pini, 2014). The metal distribution across three fractions was summed to give the bioavailable concentration. Recoveries for steps 1-3 were $98-111 \%$ (Cu) and 93-103\% (Zn). Tissue samples were also processed with mean recovery percentages of $92 \%$ for $\mathrm{Cu}$ and $99.5 \%$ for $\mathrm{Zn}$.

\subsection{RNA isolation, library preparation and sequencing}

Total RNA was extracted from the homogenised gut tissue in Tri-Reagent (see Table S1 for exposure conditions and animal numbers), purified (Direct-Zol, Zymo Research, Irvine, CA, USA), DNAse I treated (New England BioLabs, Ipswich, MA, USA), concentrated (RNA Clean \& Concentrator-5, Zymo Research) and quantified (NanoDrop ND-100, Thermo Fisher Scientific, Waltham, MA, USA), before RNA integrity was checked using agarose gel electrophoresis. RNA was pooled to form two libraries, these comprised of equimolar amounts of RNA from control and exposed samples and included animals from each time point and/or exposure (Table S1). Sequencing libraries were prepared and indexed for paired-end multiplexed sequencing (TruSeq Stranded mRNA Library Prep Kit, Illumina, San Diego, CA, USA). The validated libraries (Agilent BioAnalyser 2100, Agilent Technologies, Santa Clara, CA, USA) were pooled (8pM) and sequenced (100 bp paired-end run with 1 lane of an Illumina HiSeq2000 flow cell v3). Raw data BCL files were converted to FASTQ files and quality information assessed. (library preparation and sequencing was performed by Source BioScience, Nottingham, UK).

\subsection{Assembly, mapping, annotation and differential expression}

Raw reads were quality trimmed using Trimmomatic (Bolger et al., 2014, v. 0.32) using the following settings: Illuminaclip 2:30:10, leading $=3$, trailing $=3$ sliding window $=4 \mathrm{bp}$, quality $=15$, minimum length $=36 \mathrm{bp}$. The trimmed reads were assembled using Trinity (Grabherr et al., 2011, v. trinityrnaseq_r20140717), using the default parameters for paired-end reads with 'read normalisation', before assembled contigs were annotated using the Trinotate pipeline (Bryant et al., 2017) and a quantitative measure of 
transcriptome completeness was performed with BUSCO (Kriventseva et al., 2015) (v. 3, odb10 metazoa gene set). Reads and assembled transcriptome were deposited in NCBI: Bioproject No. PRJNA627092. Reads associated with the control and exposed samples were mapped to the transcriptome assembly [RSEM, v. 1.2.13 (Li and Dewey, 2011)]. The original counts were normalised with weighted trimmed mean of M-values (TMM) to calculate relative expression levels. As the RNASeq has no biological replication, differentially expressed transcripts were calculated using the function exactTest implemented in edgeR [v. 3.16.5 (Robinson et al., 2010)] with a common dispersion factor of 0.1. This associated a p-value with each contig sequence. The cut-off for putatively differentially expressed genes was selected experimentally using a qPCR screen. Bio- logical and molecular function analyses were performed using Panther (Thomas et al., 2003) (v. 13.1). Enriched Gene Ontology (GO) and keyword terms associated with putatively upregulated genes were determined using DAVID (Huang et al., 2009) (v. 6.7) using the following parameters: a medium classification stringency, similarity term overlap 3 , similarity threshold of 0.50 , initial group membership 3 , final group membership of 3 , and multiple linkage threshold of 0.50 . The GO terms associated with putatively up and downregulated genes was also analysed using ReviGO (Supek et al., 2011) and GOnet (Pomaznoy et al., 2018) software. For the ReviGO analysis, scored GO term lists were input (small similarity [0.5] with a SimRel semantic similarity measure). Specifically, separate scored GO term lists were created for upregulated and downregulated genes by summing fold-change levels linked to the contigs contributing to each list. GOnet analyses were performed using the log fold change values and their associated Uniprot accessions.

\subsection{Orthologue determination, sequence alignment and phylogenetic tree building}

Orthologous genes were determined using a Reciprocal Best Hit BLAST method (Moreno-Hagelsieb and Latimer, 2007) and sequence alignment, trimming and tree building were performed using Geneious (v. 8.1.9).

\subsection{Determination of stable reference genes for qPCR validation and primer design}

To develop a reliable qPCR assay, the expression of five candidate reference genes was determined using a comparative $\Delta$ Cq method (Silver et al., 2006). Briefly, a mean $\Delta \mathrm{Cq}$ value and standard deviation (std. dv.) (R, v.3.3.0) was calculated for triplicate reactions performed for each gene in twelve independent cDNA samples (representing a range of control and exposed animals). A mean (std. dv.) was calculated to reflect the expression stability of all genes relative to the remaining four candidates (ggplot2 v. 1.0.1). The two genes presenting lowest mean std. dv. were then selected as reference genes. Putative differentially expressed genes were selected on the basis of differential expression (according to RNASeq screening) across control and exposed samples. Contig sequences representing candidate reference genes (Elong-like, GAPDH-like, beta-actin-like, alpha-tubulin-like and Ubiquitin-like) and differentially expressed genes (Unk1-like, Vtg-like1, Actin-like, Calbind-like, GST-Omega-like, Unk2-like and GST-Mu-like) were used in conjunction with Primer3 software (Rozen and Skaletsky, 1999) (v. 4.1.0) to produce suitable primer sets for qPCR (Table S2).

\begin{tabular}{|c|c|c|c|c|c|c|}
\hline & & Control & Low exposure & High exposure & Low CuZn & High CuZn \\
\hline \multirow[b]{2}{*}{ 흥 } & $\begin{array}{c}\text { Nominal concentration } \\
(\mathrm{SQG}=65, \mathrm{SQGH}-270)\end{array}$ & - & 70 & 120 & 70 & 120 \\
\hline & $\begin{array}{c}\text { Sediment } \\
\text { Porewater } \\
\text { Tissue }\end{array}$ & $\begin{array}{c}6 \pm 0.2 \\
0.6 \pm 0.2 \\
9.4 \pm 0.6\end{array}$ & $\begin{array}{l}60 \pm 8.8 \\
0.9 \pm 0.1 \\
24 \pm 4.6 \\
\end{array}$ & $\begin{array}{l}125 \pm 16 \\
1.5 \pm 0.3 \\
79 \pm 26 \\
\end{array}$ & $\begin{array}{l}63 \pm 6.5 \\
1.0 \pm 0.1 \\
45 \pm 13\end{array}$ & $\begin{array}{c}81 \pm 3.5 \\
1.1 \pm 0.1 \\
57 \pm 13 \\
\end{array}$ \\
\hline \multirow[b]{2}{*}{$\stackrel{\text { c}}{\stackrel{N}{N}}$} & $\begin{array}{c}\text { Nominal concentration } \\
(\mathrm{SQG}=200, \mathrm{SQGH}-410)\end{array}$ & - & 200 & 270 & 200 & 270 \\
\hline & $\begin{array}{c}\text { Sediment } \\
\text { Porewater } \\
\text { Tissue }\end{array}$ & $\begin{array}{l}26 \pm 1.4 \\
2.2 \pm 0.7 \\
61 \pm 7.7\end{array}$ & $\begin{array}{l}180 \pm 21 \\
1.5 \pm 0.5 \\
108 \pm 7.2\end{array}$ & $\begin{array}{l}252 \pm 40 \\
1.6 \pm 0.5 \\
98 \pm 20\end{array}$ & $\begin{array}{l}163 \pm 18 \\
3.6 \pm 0.9 \\
88 \pm 5.9\end{array}$ & $\begin{array}{l}165 \pm 23 \\
3.8 \pm 1.5 \\
94 \pm 6.4\end{array}$ \\
\hline
\end{tabular}

Table 1 Copper and zinc concentrations ( 3 and 6 months combined) in $\mathrm{Cu}, \mathrm{Zn}$ and $\mathrm{Cu}-\mathrm{Zn}$ mesocosm exposures. Copper and zinc mesocosm nominal

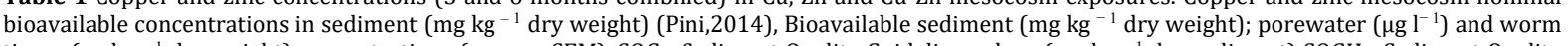
tissue ( $\mu \mathrm{g} \mathrm{kg}^{-1}$ dry weight) concentrations (mean \pm SEM). SQG - Sediment Quality Guideline values (mg kg ${ }^{-1}$ dry sediment) SQGH - Sediment Quality Guideline High value (Simpson et al., 2007). 
A representative transcriptomic atlas could be suitable for many applications. The completeness of the transcriptome can be estimated at the locus level by determining the number of near universal gene orthologues, and the extent such orthologues are present in complete or fragmented forms. The A. virens transcriptome atlas, produced using both control and exposed animals, was found to contain $99.2 \%$ (98.6\% in complete form) of the 954 genes within the BUSCO metazoan gene set (Kriventseva et al., 2015) (transcriptome statistics in Table S3). Further analysis using Panther (Thomas et al., 2003) reveals that, despite originating from a single tissue, the sequencing depth has produced a functionally representative transcriptome when compared to the Drosophila melanogaster genome (Fig. S1) (Thurmond et al., 2019). The data provided here will enable like-for-like quality comparisons of different data sets, such as comparative transcriptomic analysis. This valuable catalogue of polychaete genes can be used for many applications, including the development of probes and primers for gene expression analysis, particularly useful considering the increasing use of $A$. virens in evolutionary developmental biology (Kostyuchenko et al., 2019).

\subsection{RNASeq and qPCR screening of A.virens response to Cu-Zn exposure}

We provide evidence for differentially expressed genes by comparing the control and metal exposed samples. A single repeat RNASeq method in conjunction with a suitable statistical approach is thought capable of identifying differentially expressed genes with low fold change thresholds (Al Seesi et al., 2014). We have taken a more conservative approach, limiting ourselves to identifying genes with pronounced differential expression patterns, where the cut-off for differential expressed genes is decided using qPCR. Similar approaches have provided reliable indications of pronounced gene expression differences (Al Seesi et al., 2014; Neave et al., 2012; Short et al., 2014; Wippler et al., 2016; Robertson et al., 2017). As we used qPCR to validate the RNASeq compar ison of control and exposed animals, it was important to identify reliable reference genes. Expression of candidate reference genes (Table S4) in twelve samples from across the experiment (control and exposed) was determined using a comparative $\Delta$ Cq method (Silver et al., 2006). The Silver et al. (2006) approach has been shown comparable to other frequently used statistical approaches for determining stable reference genes (Feng et al., 2013). The stable expression suggested by the RNASeq experiment, indicated by broadly similar TMM values in control and exposed samples (Table S4) was supported by the qPCR (Fig. S2, Table S5). All five genes presented a std. dev. of less than 1 and could all be used as reference genes (Svingen et al., 2015). However, GAPDH-like and Elong-like had the greatest stability (indicated by a mean std. dev of 0.4755 and 0.5117 respectively, Table S5) and were chosen for further qPCR validations.

The expression of seven genes with a range of differential expression according to RNASeq (Table S6) were analysed by qPCR, using both GAPDH-like and Elong-like as reference genes (Fig. 1). The seven genes were selected on the basis of their association with a suitable range of p-values (determined using the exactTest) and because they represent a range of known and unknown functionality (Table S6). The qPCR experiment compared controls to biologically separate samples representing exposures to two concentrations of $\mathrm{Cu}, \mathrm{Zn}$ and $\mathrm{Cu}-\mathrm{Zn}$ for three and six months. Although variation is observed between some samples, the general expression pattern determined by qPCR agrees with the RNASeq in the p-value range $1.48 \mathrm{e}^{-11}$ to $2.7 \mathrm{e}^{-32}$.The GST-Mu-like gene, with the highest $\mathrm{p}$-value $\left(3.7 \mathrm{e}^{-09}\right)$, did not validate well, having lower expression than suggested by RNASeq (Fig. 1). Expression of both reference genes normalised to each other confirms their relatively stable expression (Fig. S3). Overall, of the 12 genes validated with qPCR, 11 correlate with the RNASeq data, 5 stable (Figs. S2 and S3) and 6 differentially expressed (Fig. 1). This suggests that any expression change in the RNASeq associated with a p-value $\leq 1.48 \mathrm{e}^{-11}$ represents a genuine expression difference.

The genes Unk1 and Vtg-like1 show a pattern of clear downregulation across both time points and all metal exposure scenarios, with the GST-Omega-like gene presenting an equivalent but upregulated expression pattern. This means the genes present strikingly similar patterns across twelve biologically independent samples, with each sample representing between 11 and 17 animals (Table S1). Therefore, it appears these gene expression responses are triggered by $\mathrm{Cu}, \mathrm{Zn}$ or a $\mathrm{Cu}-\mathrm{Zn}$ combination and appear to be maintained throughout the exposure period. For the Unk2 and the cytoskeletal-associated Actin-like and Calbind-like genes, the consistent expression between the qPCR and RNASeq only holds if expression is averaged across qPCR experiments, as there is considerable variation across samples (Fig. 1). Furthermore, the expression variation does not obviously correlate with metal concentration or exposure time (Fig. 1). The response variation may reflect the inconsistent relationship between metal concentrations in sediments and tissues (Table 1). It is possible that some gene responses are strikingly non-proportional to metal concentration. For some genes (in this case associated with the cytoskeleton), the environmentally relevant concentrations of $\mathrm{Cu} / \mathrm{Zn}$ (Table 1) may lead to varied responses if the varying metal levels in the organisms span a threshold that must be crossed to trigger cytoskeletal modifications. This hypothesis is supported by the strikingly similar pattern of variant expression across the equivalent qPCR samples for both cytoskeletal-associated genes. The similar expression pattern of Unk2 and the Actin-like and Calbind-like genes (Fig. 1) suggests Unk2 may also have cytoskeletal-functions and be induced in the same threshold dependent manner (note: the Actinlike gene is distinct from the beta- actin-like gene used in reference gene analysis). 


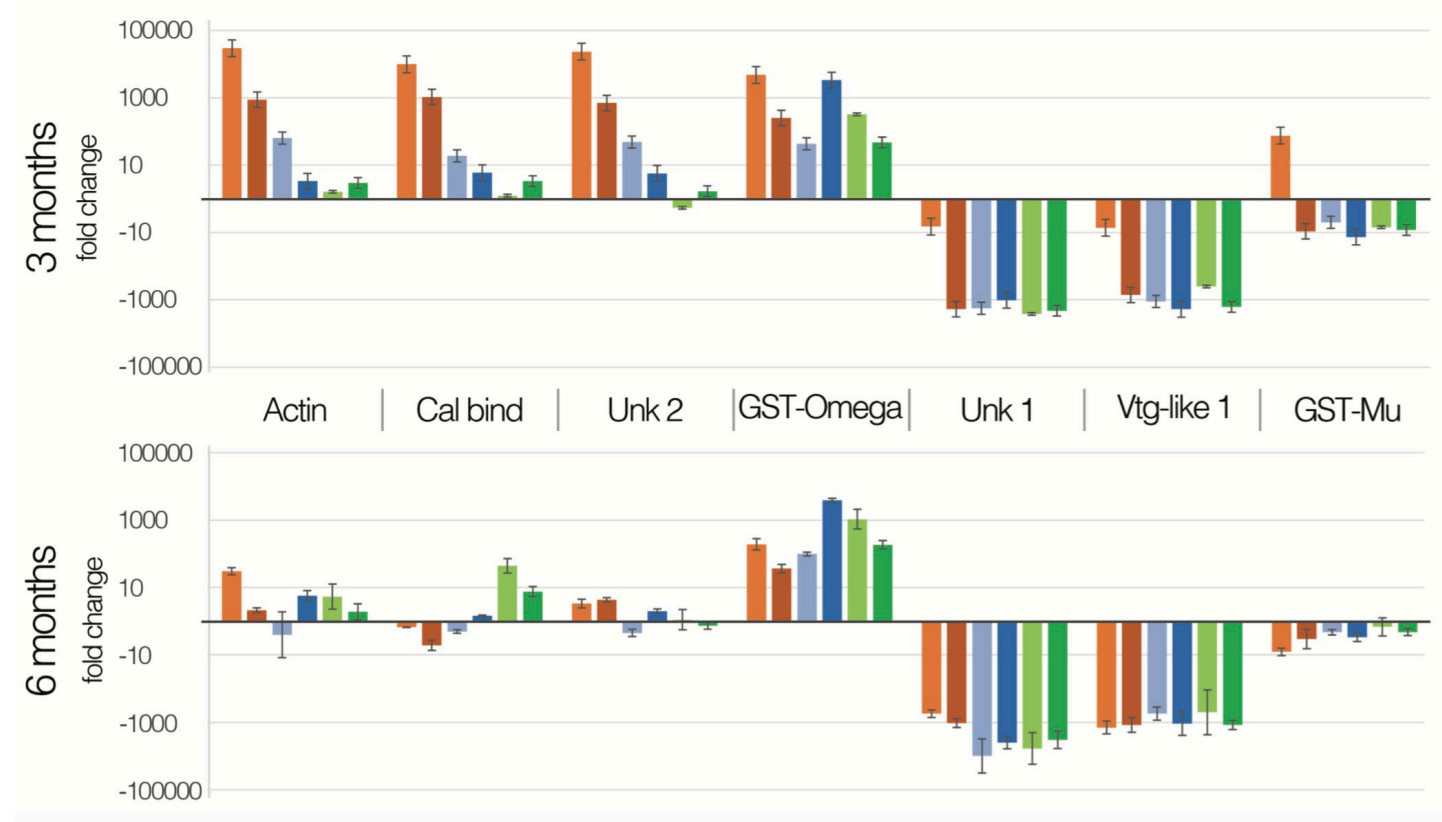

Fig. 1. Comparative $\triangle \Delta \mathrm{Cq}$ qPCR expression analysis of seven $A$. virens genes associated with a range of differential expression values suggested by RNASeq. Each column represents the average expression ( 3 technical repeats) of each sample relative to controls, all normalised to both reference genes (GAPDH-like and Elong-like). Samples were performed in triplicate and error bars represent the standard deviation. Expression was determined at two concentrations (low and high) of $\mathrm{Cu}, \mathrm{Zn}$ and $\mathrm{Cu}-\mathrm{Zn}$ for three and six months (see Table S6 for details on gene annotations and RNASeq expression).

\subsection{The challenge of finding consistent biomarkers}

A range of biomarkers have previously been suggested for monitoring metal exposure in polychaetes, selected for their putative roles in metal handling (McQuillan et al., 2014). However, these biomarkers have shown great variation, even within the same species (Breton and Prentiss, 2019; McQuillan et al., 2014). Critically, our findings suggest that the existing markers fail to present any notable differential expression between control and exposed animals (summarised in Table S7). For example, Atox1 binds and transports excess intracellular $\mathrm{Cu}$ to secretory pathways (Kim et al., 2008). Studies of Atox1 expression in polychaetes taken from heavily contaminated sites revealed significant but modest $\sim 3 \times$ upregulation in H. diversicolor using qPCR (McQuillan et al., 2014), and an even greater upregulation in Ophelina, using RNASeq and Western blot analysis (Neave et al., 2012). However, although both A. virens Atox1-like genes possess the cysteine residues necessary for Cu binding (Rosenzweig et al., 1999), the RNASeq suggests both genes have almost identical expression in control and exposed animals. Cu handling via mechanisms requiring increased Atox1 may have evolved independently in different species. Given these findings, Atox1-like genes are probably not suitable as sensitive cross-species biomarkers, despite their functional role and increased expression in some metal exposed polychaetes.

\subsection{Screening for biomarkers using GO term enrichment}

Using the qPCR-determined cut-off, we created contig lists representing genes with apparent differential expression (DE) in exposed animals. Of the 696 and 141 contigs representing up and downregulated genes respectively, 371 and 114 could be annotated via BLAST analysis against the Uniprot database (E-value cut-off $\leq 1 \mathrm{e}^{-10}$ ). The lists of Uniprot accessions were used to perform multiple analyses. Firstly, enriched Gene Ontology (GO) terms (separated into Biological Processes [BPs], Cell Components [CCs] and Molecular Functions [MFs]) associated with the accessions were determined using DAVID (Huang et al., 2009) (Figs. S4 and S5). In addition, the GO terms associated with up and downregulated genes were scored by summing fold-change levels linked to all contributing contigs. This scored GO term list was then analysed using both ReviGO (Supek et al., 2011) (Figs. 2 and S6) to reveal highly expressed GOterms and GOnet software (Pomaznoyetal., 2018) (Figs. S7 and S8) to reveal their various relationships.

The analysis of upregulated genes reveals clear enrichment of G0 terms associated with cilia function (Figs. 2, S4, S7 and S8). These are largely represented by a suite of axonemal dynein genes, with a broad range of cilia-associated genes representing the remaining GO term 'cilium'. The modest enrichment of the KOG functional group 'cell motility' in the metal-exposed polychaete Ophelina (Neave et al., 2012) suggests a somewhat similar response may occur across polychaetes. Assuming the modified cytoskeletal gene expression is adaptive, it is possible to speculate on its functional role. As the intestinal epithelium of polychaetes possesses many ciliated cell types (Kermack, 1955) that come into contact with contaminated sediment, the enrichment of cilium-associated GO terms could 
represent attempts to replace damaged cilia. This response may also represent mechanisms that aid metal removal, as cilia in both invertebrates and vertebrates possess 'ciliary pockets' thought to be involved in vesicular trafficking (Benmerah, 2013). Indeed, gene expression suggests earthworms use a cilium-based system to sense and transport silver (Novo et al., 2015).

The analyses also provide evidence for upregulation/enrichment of GO terms broadly associated with cytoskeletal and microtubulerelated functions (Figs. S4 and S8). Cytoskeletal-associated genes are enriched in both Ophelina exposed to Cu/Zn (Neave et al., 2012) and the earthworm Lumbricus rubellus exposed to cadmium (Owen et al., 2008). The cytoskeleton is an early target of oxidative damage (Dalle-Donne et al., 2001) and normal reactive oxygen species (ROS) concentrations are critical for regular cytoskeletal remodelling and function (Sakai et al., 2012; Wilson and González-Billault, 2015). Therefore, the metal- exposure may lead to dysfunctional changes to the cytoskeletal composition. However, the expression alterations may be adaptive to some degree, as cytoskeletal changes can act as a signalling mechanism for oxidative stress in diverse organisms (Clark et al., 2018; Farah and Amberg, 2007) and play critical roles in the repair of damaged cells (Abreu-Blanco et al., 2012). The cytoskeletal GO terms enriched in Ophelina and A. virens are not represented by the same gene sets (Neave et al., 2012). To some extent, this likely reflects the different tissues assayed (whole body versus gut tissue). It may also reflect the evolution of divergent response mechanisms, resulting from the multigeneration field exposure of Ophelina (Neave et al., 2012), compared to the exposed A. virens being taken from a relatively clean site. In support of this hypothesis, metal exposure of the polychaete H. diversicolor, taken from both metal-contaminated and clean sites, revealed animals originally from the contaminated-site possess more efficient strategies for sequestering and excreting metals (Mouneyrac et al., 2003). Specifically, the gut epithelium of exposed contaminated-site worms presented abundant Cu-containing lysosomes and extracellular granules, whereas exposed clean-site worms either lacked or possessed greatly reduced equivalent structures. Furthermore, while 'spherocrystals' were observed in the gut of both exposed clean and contaminated-site worms, these structures only act as a detoxified Zn store in the latter (Mouneyrac et al., 2003).

Enriched GO terms, associated with collagen metabolism and the extracellular matrix (Fig. S4), are dominated by a series of matrix metalloproteinases (MMPs) and these genes are also components of several prominent terms in the ReviGO analysis, such as 'Zinc ion binding' (Fig. 2). Further insight into the likely role of MMPs is given by their inclusion in the highly expressed terms 'proteolysis' (Fig. 2) and 'proteinaceous extracellular matrix' (Fig. S4), where they are combined with other ECM-related proteins including multiple collagen $\alpha$-chains. Taken together, these provide clear evidence of increased ECM remodelling in exposed animals. Collagens dominate the ECM and MMPs are critical to their degradation and modification (Lu et al., 2011), with increased MMP expression and activity observed in vertebrates exposed to oxidative stress (Alge-Priglinger et al., 2009; Siwik et al., 2001). Although knowledge of ECM remodelling is primarily based on vertebrate systems, extrapolation is reasonable as major ECM components and MMP functionalities are conserved across metazoans (Özbeketal., 2010; Page-McCaw, 2008). On this basis, the presence of ECM and MMP GO terms may be explained if metal-induced ROS damage to intestinal cells induces repair mechanisms that involve substantial ECM remodelling. Not surprisingly, given the conservation of ECM-related genes, there is evidence of similar responses in other polychaetes. For example, even though direct comparisons of contributing genes are not possible, the KOG term 'extracellular structures' is also enriched in Ophelina from metal contaminated sites (Neave et al., 2012).
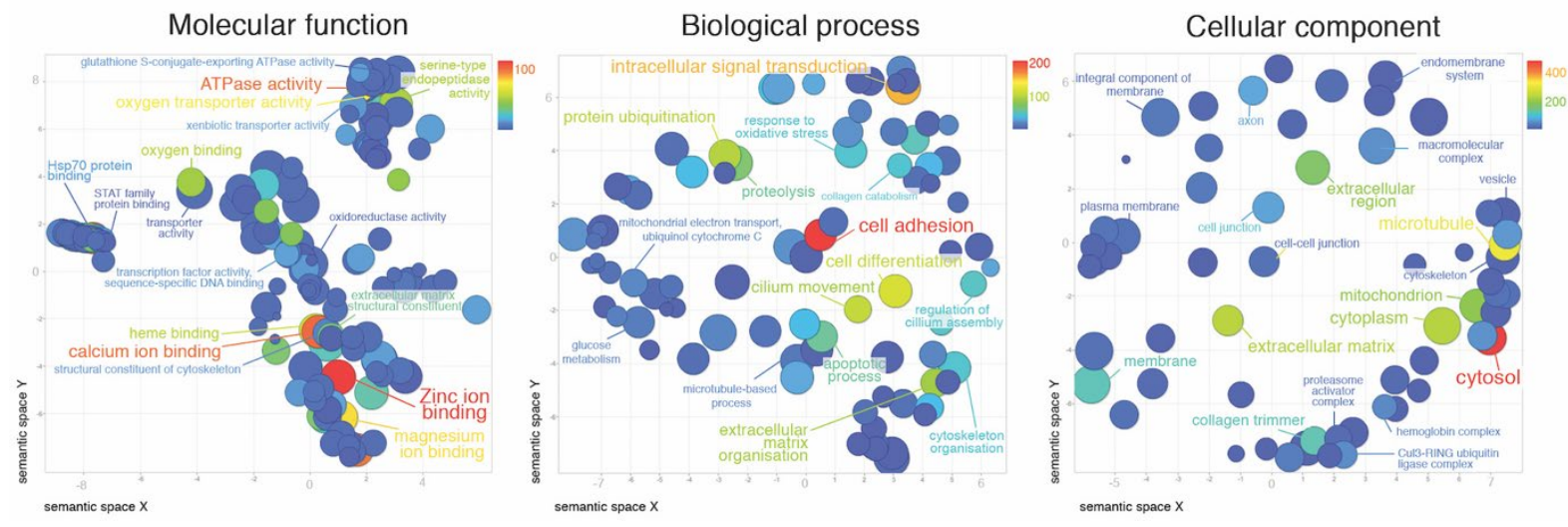

Fig. 2. Summarised ReviGO analysis of 'Molecular Function', 'Biological Process' and 'Cell Component' Gene Ontology (GO) terms associated with putatively upregulated genes. GO terms associated with relevant genes were scored by summing fold-change levels linked to contributing contigs. The scored GO term list was then subsequently analysed using ReviGO.

Other genes with established links to responses to cell damage. For example, E3 ubiquitin ligase that contributes to the GO term 'protein ubiquitination' (Fig. 2), has known roles in mediating response to oxidative stress (Wolyniec et al., 2013). Furthermore, the enriched 'Cul3-RING ubiquitin ligase complex' (Fig. 2) is dominated by highly conserved kelch-like proteins, which function as critical components of the ubiquitin-proteasome system (Gupta and Beggs, 2014). In addition, in mammalian cells, kelch proteins bound to metals can activate a battery of genes important for cell survival against oxidative and other stressors (He and Ma, 2010).

We observe high expression of genes associated with the GO terms 'oxygen binding', 'oxygen transporter activity' and 'heme binding' (Fig. 2). We also observe notable enrichment of GO terms 'oxygen transport' and hemoglobin complex' in the DAVID analysis (Fig. 
S4). The term 'heme binding' includes a dual oxidase, a gene that, in vertebrates, responds to chemical-induced epithelial injury by promoting expression of genes critical to wound response, such as MMPs (van der Vliet et al., 2018). The increased expression of both dual oxidase and MMPs (see above) in exposed A. virens suggests a similar mechanism may be activated in the damaged gut epithelium of polychaetes. A suite of globin subunit and globin linker chains constitute the remaining genes in these GO terms. Although their role in metal-response is uncertain (considered in more detail below), it is striking that globin subunits in Ophelina from metal contaminated sites also present dramatically increased expression (Neave et al., 2012).

The GO term 'ATPase activity' is associated with highly upregulated genes (Fig. 2) and, although the contributing genes are functionally diverse, they all have plausible links to metal response. As well as cytoskeletal-related kinesin-like proteins, we observe upregulation of ATP-binding cassette sub-family E member 1 (ABCE1). This highly conserved gene, critical to protein synthesis, has particularly ROS-labile cofactors (Fe-S clusters) (Alhebshi et al., 2012). Interestingly, increasing ABCE1 expression in yeast rescues ROS toxicity, possibly because Fe-S sequestration into ABCE1 decreases the pool of ROS-sensitive Fe-S clusters (Alhebshi et al., 2012). The upregulation of ABCE1 suggests a similar mechanism in metal-exposed A. virens. The Multidrug resistance- associated protein 1 (MRP1) also contributes to this GO term. MRP1 is a membrane pump that mediates the efflux of a wide variety of xenobiotics, including glutathione conjugates, and is critical to protecting cells against a range of toxic compounds (Cole, 2014). The upregulation of MRP1 in concert with specific Glutathione S-transferases (GSTs) (see discussion of GST-Omega below) provides a metal-detoxification/efflux pathway. Interestingly, we also see upregulation of Unconventional myosin-XIX (Myo19), an ATPase critical to the ROS-induced mitochondria localisation to filopodia (Shneyer et al., 2016). Mitochondria play complex roles in stressed cells and can migrate within the cell to supply local ATP demand or provide a localised signalling platform (Shneyer et al., 2016; Tait and Green, 2012). If such mitochondrial re-localisation is occurring in A. virens, it may also explain some proportion of the upregulated cytoskeleton associated genes. The final contributing gene to this GO term is Heat shock cognate $71 \mathrm{kDa}$ protein (Hspa8), a highly conserved molecular chaperone implicated in the protection of the proteome from metal-induced stress (Kwon et al., 2013), that has also been found upregulated in the polychaete Perinereis nuntia taken from a metal contaminated site (Rhee et al., 2012).

Enrichment of specific GO terms was also observed in the relatively fewer downregulated genes, although with higher enrichment pvalues (Fig. S5). GO terms linked with cell junction/cell adhesion are a major feature of the DAVID and ReviGO output (Figs. S5 and S6). Downregulation of genes contributing to these groups might be related to ECM remodelling and wound-healing (supported by the upregulation of MMPs and other ECM-related genes). Furthermore, ROS can disrupt cell-cell junctions between epithelial cells (Narimatsu et al., 2013) and reductions of cell-junction associated proteins appears critical to normal wound-healing in Drosophila embryos (Hunter et al., 2015). Terms linked to ion channel/ion transport also appear in the various analyses (Figs. S5 and S6). The reason for this downregulation is unclear but oxidative stress is known to modulate ion channel activity (Kiselyov and Muallem, 2016), possibly the result of considerable 'cross-talk' between REDOX and calcium signalling (Hidalgo and Donoso, 2008).

\subsection{Mining for conserved and new biomarkers}

We further mined the validated gene list $\left(\leq 1.48 \mathrm{e}^{-11}\right)$ to identify additional biomarkers, looking for genes known to be modulated by metal exposure in polychaetes and annelids (McQuillan et al., 2014; Mouneyrac et al., 2003; Neave et al., 2012; Novo et al., 2015; Rhee et al., 2007a, 2007b, 2012). We also include genes that have not been previously identified as polychaete biomarkers but, given their functional roles, plausibly represent reliable and sensitive indicators of heavy metal exposure (summarised in Table 2).

\subsection{Glutathione S-transferases (GSTs)}

GSTs conjugate glutathione to xenobiotic substrates (including metals) to facilitate detoxification via ATP-dependent pumps (Ishikawa, 1992). GST-Omega-like genes are associated with oxidative stress response (Kim et al., 2008) and are upregulated in several metal-exposed polychaete species, specifically Hediste diversicolor from metal contaminated sites (McQuillan et al., 2014), Alitta succinea exposed to cadmium (Won et al., 2011) and Cu-exposed Perinereis nuntia (Rhee et al., 2007a, 2012). Both the RNASeq and qPCR reveal upregulation of a GST-Omega- like gene in exposed A. virens (Table 2). However, sequence analysis reveals the closest $A$. virens homolog to the upregulated $A$. succinea and $P$. nuntia genes are not upregulated in $A$. virens. Furthermore, even within the same species, GST-Omega expression appears to vary dramatically between Cu contaminated sites (Breton and Prentiss, 2019; McQuillan et al., 2014). This divergence suggests independent evolution of GST-Omega response between polychaete species. Overall, the upregulation across polychaetes suggest GST-Omega genes play important roles in metal detoxification but, as the induced homolog varies between species, no single gene is an obvious cross-species biomarker. 


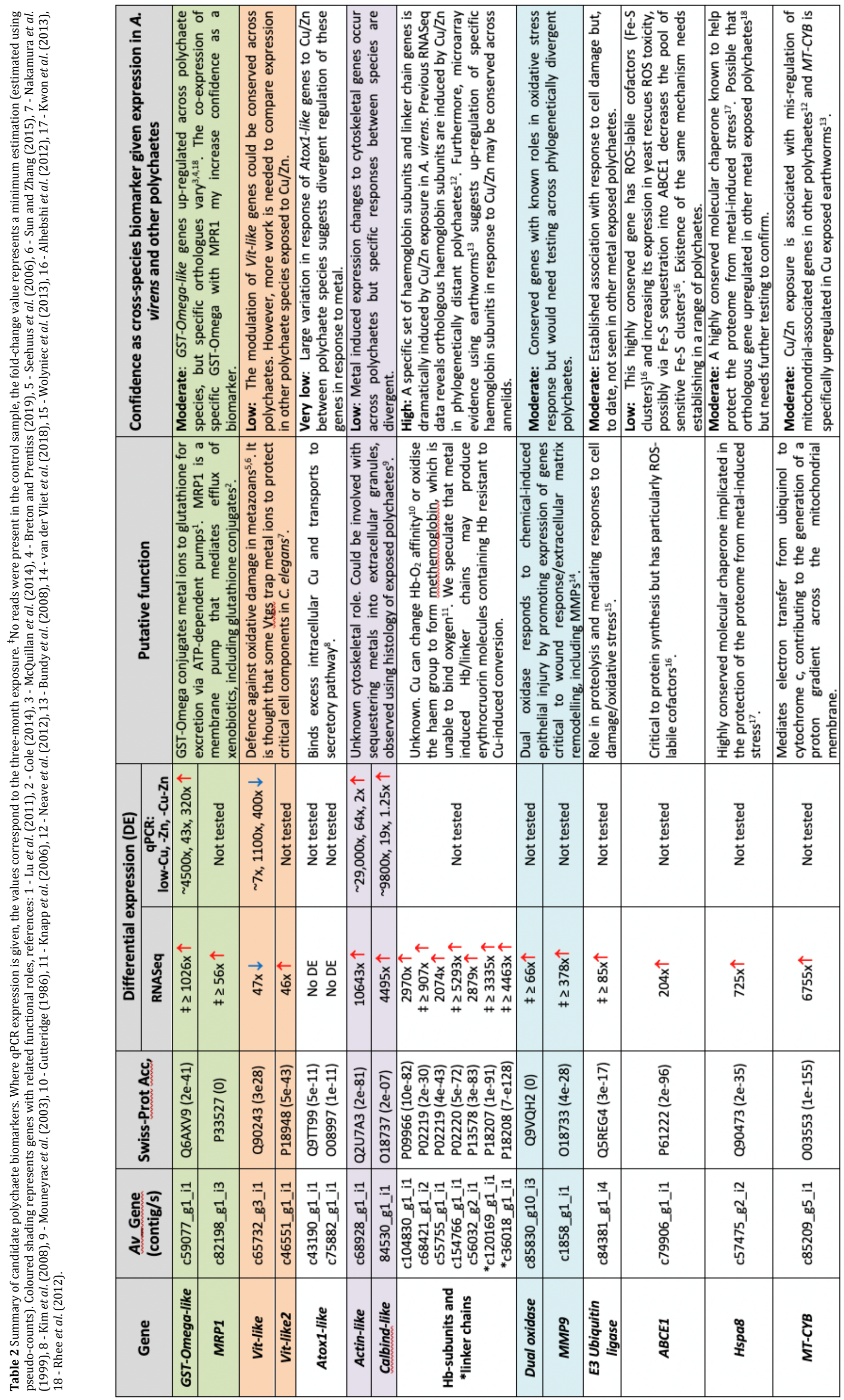


Our analysis reveals opposite expression responses of different vitellogenin-like (Vtg-like) genes in exposed animals, a clear downregulation of Vtg-like and contrasting up-regulation of Vtg-like2 (Table 2). It is not clear whether these expression changes represent metal-induced dysfunction or an adaptive response mechanism to mitigate the effects of exposure. However, there is enough evidence to hypothesise a functional role, in addition to its role as a precursor of egg- yolk protein (Matozzo et al., 2008), as it is clear Vtg also protects cells from ROS damage across metazoa (Nakamura et al., 1999; Seehuus et al., 2006; Sun and Zhang, 2015). The oxidative stress associated with metal exposure may lead to the replacement of Vtg-like proteins with versions that offer better protection, perhaps with increased capacities to trap metal ions (Nakamura et al., 1999). No changes to Vtg-like gene expression were observed in the polychaete Ophelina from a Cu-Zn contaminated site (Neave et al., 2012). However, the relatively limited sequencing depth employed for Ophelina makes it unlikely the equivalent $V t g$ gene expression changes would be observed. Overall, further work is required to elucidate Vtg's role in polychaete metal/stress response and to determine if these metal-induced expression changes play a functional and conserved role across species.

\subsection{Actin-like, Calbind-like and other cytoskeletal associated genes}

The large number of cytoskeletal-associated genes upregulated in metal exposed A. virens and Ophelina (Neave et al., 2012) (Fig. S4) suggest these genes might be suitable biomarkers. However, the cytoskeletal-associated genes upregulated in A. virens and Ophelina are not orthologous and there is no evidence for universal markers. Furthermore, although the qPCR and RNASeq reveal upregulation of the Actin-like and Calbind-like genes in A. virens, the extent of upregulation is extremely variant across samples (Fig. 1). The interplay of factors contributing to cytoskeletal responses is not clear and could be linked to population exposure histories (Mouneyrac et al., 2003). Therefore, currently these genes are not suitable biomarkers of metal response (Table 2).

\subsection{Complexes of the electron transport chain}

Mitochondrial gene mis-regulation has been seen in Cu-exposed earthworms (Bundy et al., 2008) and there are established links between metal exposure and mitochondrial dysfunction (Sharpley and Hirst, 2006). The upregulation of the mitochondrial gene Cytochrome b $(C y t B)$ in $A$. virens, in a manner strikingly similar to that seen in $\mathrm{Cu}$ - exposed earthworms (Bundy et al., 2008), suggests a plausible biomarker for metal (or at least $\mathrm{Cu}$ ) exposure (Table 2).

\subsection{Haemoglobin $(\mathrm{Hb})$ subunits and linker chains}

The enrichment of the GO terms associated with 'oxygen transport' and the 'hemoglobin complex' (Fig. S4) is predominantly due to the upregulation of multiple haemoglobin $(\mathrm{Hb})$ subunits and globin linker chains. Annelids, including A. virens, contain giant freely dissolved 'erythrocruorin' respiratory proteins (Hackert and Riggs, 2006; Weber, 1978). These proteins are assembled from multiple $\mathrm{Hb}$ subunits and linker chains (Knapp et al., 2006) and have been linked to polychaete metal response (e.g. Neave et al., 2012). The Ophelina transcriptome contained three $\mathrm{Hb}$ subunits that include the two paralogues $H b B 1 a$ and $H b B 1 b$. Critically, while $H b B 1 b$ was consistently expressed, HbB1a presented dramatic upregulation in animals from a contaminated site (Neave et al., 2012) (Figs. 3 and S9). The A. virens transcriptome contains eleven $\mathrm{Hb}$ subunit genes (5 paralogue pairs) and four Hb linker chain genes (2 paralogue pairs). These sequences likely represent distinct paralogous genes, as the amino acid identity between the most closely related sequences is $\sim 90 \%$, suggesting too much divergence for allelic variants. Furthermore, given the allelic homogeneity of the animals pooled for RNA samples, the sequences are unlikely to represent polymorphic alleles from divergent genotypes. Interestingly, in a manner strikingly similar to Ophelina (Neave et al., 2012), for each paralogue pair in A. virens, one is expressed consistently and the other is essentially only expressed in exposed animals (Fig. 3 and Table S8). Differences in the number of Hb subunits found in Ophelina by in Neave et al. (2012) and A. virens likely results from the considerable difference in sequencing depth $(\sim 650 \mathrm{~K}$ reads for Ophelina (Neave et al., 2012) and 390 million for A. virens, Table S3). In Cu-exposed earthworms, upregulation of a Hb subunit in a Lumbricus rubellus microarray study (Bundy et al., 2008) and increased total Hb levels in metal exposed Lumbricus terrestris (Calisi et al., 2011, 2013) suggest $\mathrm{Hb}$ upregulation may be a general annelid mechanism. 


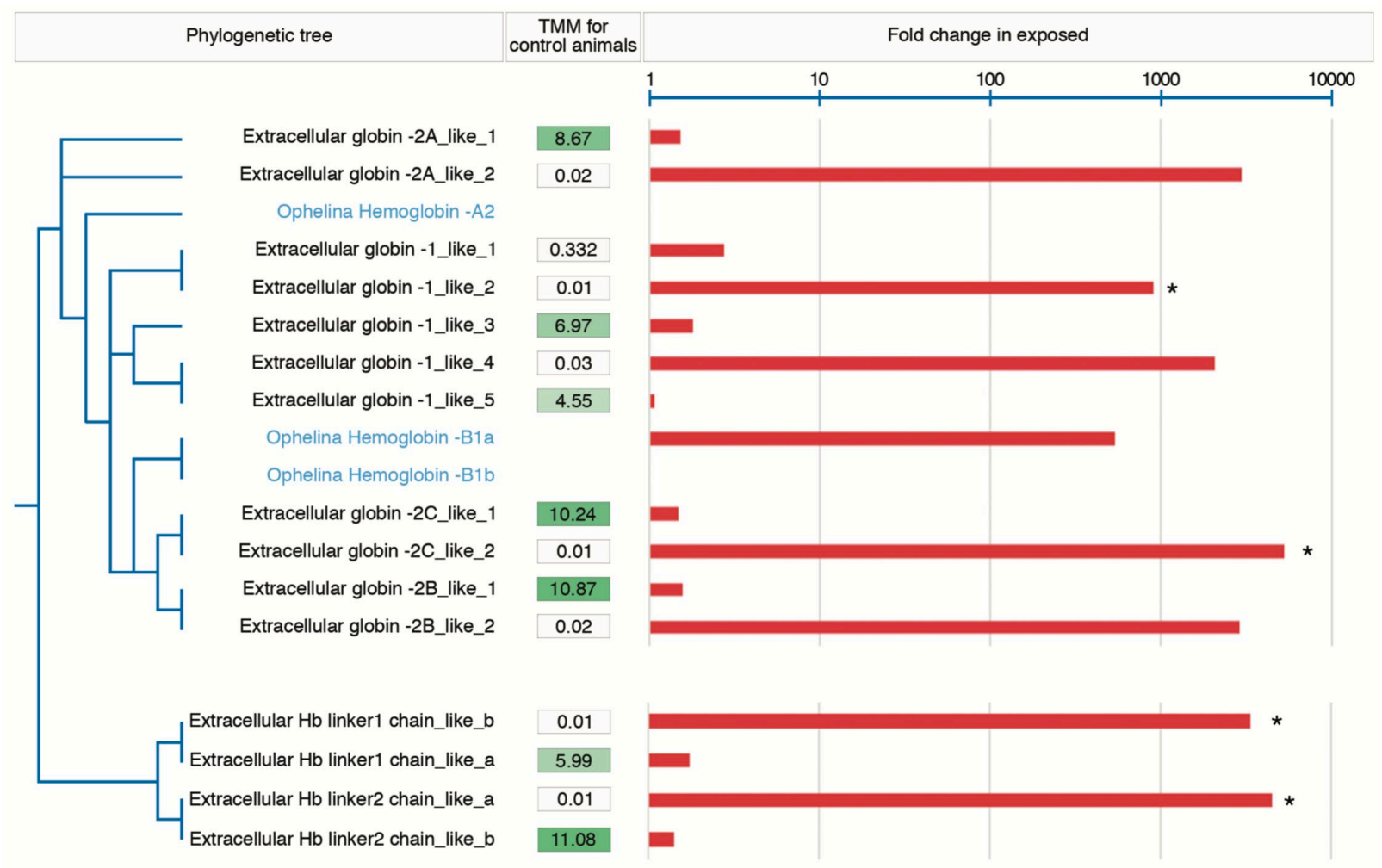

Fig. 3. Haemoglobin ( $\mathrm{Hb}$ ) subunit and linker chain expression changes in the polychaetes Alitta virens and Ophelina (Neave et al., 2012) exposed to metals. Expression observed in control animals is expressed as TMM (white to dark green shows low to high expression respectively). Expression of Ophelina genes A2 and B1b is not published but no differential expression was reported. *No reads were present in the control sample, the fold-change value represents a minimum estimation, Ophelina Haemoglobin-B1a is based on published read counts (Neave et al., 2012). (For interpretation of the references to colour in this figure legend, the reader is referred to the web version of this article.)

Assuming the upregulation of the $\mathrm{Hb}$ subunits and linker chains represents an adaptive response to stress, their exact role is uncertain. However, their conserved induction across polychaetes is consistent with an important function. It is possible the upregulated subunits and linkers may act in combination with the constitutive genes to produce modified erythrocruorins. However, the coexpression of a large repertoire of subunit and linkers could, at least in theory, lead to the production of entirely distinct erythrocruorins (Knapp et al., 2006; Weber, 1978). The subunit upregulation may reflect the need for a greater capacity to transport oxygen when under metal-induced stress, however, the negligible expression in unexposed animals (Fig. 3) suggests that their presence may be counter-productive under normal conditions. Hbs isolated from the blood of polychaetes binds to toxic heavy metals (Demuynck and Dhainaut-Courtois, 1993) and, despite being a critical component of annelid biology (Weber, 1978), Hbs are degraded by ROS and vulnerable to metal exposure (Gutteridge, 1986). Specifically, polychaete erythrocruorin oxygen affinity is altered by $\mathrm{Cu} / \mathrm{Zn}$ (Everaarts et al., 1979) and $\mathrm{Cu}$ exposure can oxidise earthworm $\mathrm{Hb}$ to produce methaemoglobin, a form that is unable to bind oxygen (Calisi et al., 2011). We propose that erythrocruorin produced using the induced genes are resistant to some combination of ROS damage, harmful changes to oxygen affinity, or Hb-methaemoglobin conversion. The hypothesis that modified Hbs can mitigate toxicity is supported by evidence that free cysteines on specific $\mathrm{Hb}$ subunits bind hydrogen sulphide in sulphide-rich environments (Bailly et al., 2002; Chabasse et al., 2006). This capacity may extend beyond polychaetes, as a transcriptomic survey suggests that divergent $\mathrm{Hb}$ subunits, in the oligochaete Olavius algarvensis, are able to reduce the harmful effects of hydrogen sulphide produced by bacterial symbionts (Wippler et al., 2016). Further evidence comes from the polychaete Amphitrite ornata that possesses a dehaloperoxidase, evolved from an oxygen carrying haemoglobin, capable of breaking down volatile metabolites secreted as repellents by organisms cohabiting the same ecosystem (Lebioda et al., 1999; Barrios et al., 2014). Overall, the use of modified Hbs by polychaetes to mitigate environmental stress may be more of a rule than an exception. To determine if the $\mathrm{Hb}$ induction is as conserved as suggested by the $A$. virens and Ophelina data, the upregulation of $\mathrm{Hb}$ subunits and linkers needs to be confirmed in other polychaete species. Also, $\mathrm{Hb}$ induction needs to be measured following exposure to specific metals and a range of other stressors, as such data should reveal insights into whether the induced subunits are critical to mitigating the specific effects of metal exposure, or play more general roles in stress response. So, although more work needs to be done, independent evidence of dramatic Hb subunit upregulation in relatively divergent polychaetes, exposed in field and mesocosm scenarios, suggests the Hb subunits could be a conserved and sensitive marker of metal exposure. 
The authors declare no competing financial interest. All sequencing data (both sequencing reads and the transcriptome assembly) will be made available through Genbank (NCBI), BioProject number: PRJNA627092.

\section{Declaration of competing interest}

The authors declare that they have no known competing financial interests or personal relationships that could have appeared to influence the work reported in this paper.

\section{Acknowledgements}

This work was supported by European RDF (Interreg) grants IVA 3C and CHRONEXPO.

\section{Appendix A. Supplementary data}

Supplementary data to this article can be found online at https://doi. org/10.1016/j.cbpc.2020.108913.

\section{References}

Abreu-Blanco, M.T., Watts, J.J., Verboon, J.M., Parkhurst, S.M., 2012. Cytoskeleton responses in wound repair. Cell. Mol. Life Sci. 69, $2469-2483$.

Al Seesi, S., Tiagueu, Y.T., Zelikovsky, A., Mandoiu, I.I., 2014. Bootstrap-based differential gene expression analysis for RNA-Seq data with and without replicates. BMC Genomics 15 , S2.

Alge-Priglinger, C.S., Kreutzer, T., Obholzer, K., Wolf, A., Mempel, M., Kernt, M., Kampik, A., Priglinger, S.G., 2009. Oxidative stress-mediated induction of MMP-1 and MMP-3 in human RPE cells. Invest. Ophthalmol. Vis. Sci. 50, 5495-5503.

Alhebshi, A., Sideri, T.C., Holland, S.L., Avery, S.V., 2012. The essential iron-sulfur protein Rli1 is an important target accounting for inhibition of cell growth by reactive oxygen species. Mol. Biol. Cell 23, 3582-3590.

Amiard, J.-C., Geffard, A., Amiard-Triquet, C., Crouzet, C., 2007. Relationship between the lability of sediment-bound metals (Cd, Cu, Zn) and their bioaccumulation in benthic invertebrates. Estuar. Coast. Shelf Sci. 72, 511-521.

Bailly, X., Jollivet, D., Vanin, S., Deutsch, J., Zal, F., Lallier, F., Toulmond, A., 2002. Evolution of the sulfide-binding function within the globin multigenic family of the deep-sea hydrothermal vent tubeworm Riftia pachyptila. Mol. Biol. Evol. 19, 1421-1433.

Barrios, D.A., D’Antonio, J., McCombs, N.L., Zhao, J., Franzen, S., Schmidt, A.C., Sombers, L.A., Ghiladi, R.A., 2014. Peroxygenase and oxidase activities of dehaloperoxidase-hemoglobin from Amphitrite ornata. J. Am. Chem. Soc. 136, 7914-7925.

Benmerah, A., 2013. The ciliary pocket. Curr. Opin. Cell Biol. 25, 78-84.

Bolger, A.M., Usadel, B., Lohse, M., 2014. Trimmomatic: a flexible trimmer for Illumina sequence data. Bioinformatics 30, 2114-2120.

Breton, T.S., Prentiss, N.K., 2019. Metal stress-related gene expression patterns in two marine invertebrates, Hediste diversicolor (Annelida, Polychaeta) and Littorina littorea (Mollusca, Gastropoda), at a former mining site. Comp. Biochem. Physiol. C Toxicol. Pharmacol. $225,108588$.

Bryan, G., Langston, W., 1992. Bioavailability, accumulation and effects of heavy metals in sediments with special reference to United Kingdom estuaries: a review. Environ. Pollut. 76, 89-131.

Bryant, D.M., Johnson, K., DiTommaso, T., Tickle, T., Couger, M.B., Payzin-Dogru, D., Lee, T.J., Leigh, N.D., Kuo, T.-H., Davis, F.G., 2017. A tissuemapped axolotl de novo transcriptome enables identification of limb regeneration factors. Cell Rep. 18, 762-776.

Bundy, J.G., Sidhu, J.K., Rana, F., Spurgeon, D.J., Svendsen, C., Wren, J.F., Stürzenbaum, S.R., Morgan, A.J., Kille, P., 2008. 'Systems toxicology' approach identifies coordinated metabolic responses to copper in a terrestrial non-model invertebrate, the earthworm Lumbricus rubellus. BMC Biol. 6, 25.

Calisi, A., Lionetto, M.G., Sanchez-Hernandez, J.C., Schettino, T., 2011. Effect of heavy metal exposure on blood haemoglobin concentration and methemoglobin percentage in Lumbricus terrestris. Ecotoxicology 20, 847.

Calisi, A., Zaccarelli, N., Lionetto, M.G., Schettino, T., 2013. Integrated biomarker analysis in the earthworm Lumbricus terrestris: application to the monitoring of soil heavy metal pollution. Chemosphere 90, 2637-2644.

Caplat, C., Texier, H., Barillier, D., Lelievre, C., 2005. Heavy metals mobility in harbour contaminated sediments: the case of Port-en-Bessin. Mar. Pollut. Bull. 50, 504-511.

Chabasse, C., Bailly, X., Rousselot, M., Zal, F., 2006. The multigenic family of the extracellular hemoglobin from the annelid polychaete Arenicola marina. Comp. Biochem. Physiol. B: Biochem. Mol. Biol. 144, 319-325.

Clark, M.S., Thorne, M.A.S., King, M., Hipperson, H., Hoffman, J.I., Peck, L.S., 2018. Life in the intertidal: cellular responses, methylation and epigenetics. Funct. Ecol. 32, 1982-1994. 
Cole, S.P., 2014. Multidrug resistance protein 1 (MRP1, ABCC1), a "multitasking” ATP- binding cassette (ABC) transporter. J. Biol. Chem. 289, 3088030888.

Dalle-Donne, I., Rossi, R., Milzani, A., Di Simplicio, P., Colombo, R., 2001. The actin cytoskeleton response to oxidants: from small heat shock protein phosphorylation to changes in the redox state of actin itself. Free Radic. Biol. Med. 31, 1624-1632.

Dean, H.K., 2008. The use of polychaetes (Annelida) as indicator species of marine pollution: a review. Rev. Biol. Trop. 56, 11-38.

Demuynck, S., Dhainaut-Courtois, N., 1993. Identification of extracellular haemoglobin as the major high molecular weight cadmium-binding protein of the polychaete annelid Nereis diversicolor. Comp. Biochem. Physiol. C: Pharmacol. Toxicol. Endocrinol. 106, 467-472.

Everaarts, J., Osborne, W., Verhaaf, E., 1979. Effect of copper and zinc on some oxygen binding properties of the haemoglobin of the polychaete Arenicola marina. Neth. J. Sea Res. 13, 571-580.

Farah, M.E., Amberg, D.C., 2007. Conserved actin cysteine residues are oxidative stress sensors that can regulate cell death in yeast. Mol. Biol. Cell $18,1359-1365$.

Feng, L., Yu, Q., Li, X., Ning, X., Wang, J., Zou, J., Zhang, L., Wang, S., Hu, J., Hu, X., Bao, Z., 2013. Identification of reference genes for qRT-PCR analysis in Yesso Scallop Patinopecten yessoensis. PLoS One 8, e75609.

Gao, Y., Luo, Z., He, N., Wang, M.K., 2013. Metallic nanoparticle production and consumption in China between 2000 and 2010 and associative aquatic environmental risk assessment. J. Nanopart. Res. 15, 1681.

Garc^es, J., Costa, M.H., 2009. Trace metals in populations of Marphysa sanguinea (Montagu, 1813) from Sado estuary: effect of body size on accumulation. Sci. Mar. 73, 605-616.

Giangrande, A., Licciano, M., del Pasqua, M., Fanizzi, F.P., Migoni, D., Stabili, L., 2017. Heavy metals in five Sabellidae species (Annelida, Polychaeta): ecological implications. Environ. Sci. Pollut. Res. 24, 3759-3768.

Grabherr, M.G., Haas, B.J., Yassour, M., Levin, J.Z., Thompson, D.A., Amit, I., Adiconis, X., Fan, L., Raychowdhury, R., Zeng, Q., 2011. Full-length transcriptome assembly from RNA-Seq data without a reference genome. Nat. Biotechnol. 29, 644.

Grant, A., Hateley, J.G., Jones, N.V., 1989. Mapping the ecological impact of heavy metals on the estuarine polychaete Nereis diversicolor using inherited metal tolerance. Mar. Pollut. Bull. 20, 235-238.

Gupta, V.A., Beggs, A.H., 2014. Kelch proteins: emerging roles in skeletal muscle development and diseases. Skelet. Muscle 4, 11.

Gutteridge, J.M., 1986. Iron promoters of the Fenton reaction and lipid peroxidation can be released from haemoglobin by peroxides. FEBS Lett. 201, 291-295.

Hackert, M.L., Riggs, A.F., 2006. When size matters. Structure 14, 1094-1096.

He, X., Ma, Q., 2010. Critical cysteine residues of Kelch-like ECH-associated protein 1 in arsenic sensing and suppression of nuclear factor erythroid 2-related factor 2. J. Pharmacol. Exp. Ther. 332, 66-75.

Hidalgo, C., Donoso, P., 2008. Crosstalk between calcium and redox signaling: from molecular mechanisms to health implications. Antioxid. Redox Signal. 10, 1275-1312.

Hook, S.E., Gallagher, E.P., Batley, G.E., 2014. The role of biomarkers in the assessment of aquatic ecosystem health. Integr. Environ. Assess. Manag. $10,327-341$.

Huang, D.W., Sherman, B.T., Zheng, X., Yang, J., Imamichi, T., Stephens, R., Lempicki, R. A., 2009. Extracting biological meaning from large gene lists with DAVID. Curr. Protoc. Bioinformatics 13 (27), 11.

Hunter, M.V., Lee, D.M., Harris, T.J., Fernandez-Gonzalez, R., 2015. Polarized E- cadherin endocytosis directs actomyosin remodeling during embryonic wound repair. J. Cell Biol. 210, 801-816.

Ishikawa, T., 1992. The ATP-dependent glutathione S-conjugate export pump. Trends Biochem. Sci. 17, 463-468.

Johnson, A.C., Donnachie, R.L., Sumpter, J.P., Jürgens, M.D., Moeckel, C., Pereira, M.G., 2017. An alternative approach to risk rank chemicals on the threat they pose to the aquatic environment. Sci. Total Environ. 599, 1372-1381.

Kermack, D.M., 1955. The anatomy and physiology of the gut of the polychaete Arenicola marina (L.). Proc. Zool. Soc. London 125, 347-381.

Kim, B.-E., Nevitt, T., Thiele, D.J., 2008. Mechanisms for copper acquisition, distribution and regulation. Nat. Chem. Biol. 4, 176.

King, C., Dowse, M., Simpson, S., Jolley, D., 2004. An assessment of five Australian polychaetes and bivalves for use in whole-sediment toxicity tests: toxicity and accumulation of copper and zinc from water and sediment. Arch. Environ. Contam. Toxicol. 47, 314-323.

Kiselyov, K., Muallem, S., 2016. ROS and intracellular ion channels. Cell Calcium 60, 108-114.

Knapp, J.E., Pahl, R., Šrajer, V., Royer, W.E., 2006. Allosteric action in real time: time- resolved crystallographic studies of a cooperative dimeric hemoglobin. Proc. Natl. Acad. Sci. 103, 7649-7654. 
Kostyuchenko, R.P., Kozin, V.V., Filippova, N.A., Sorokina, E.V., 2019. FoxA expression pattern in two polychaete species, Alitta virens and Platynereis dumerilii: examination of the conserved key regulator of the gut development from cleavage through larval life, postlarval growth, and regeneration. Dev. Dyn. 248, 728-743.

Kristensen, E., Kostka, J., 2005. Macrofaunal Burrows and Irrigation in Marine Sediment: Microbiological and Biogeochemical. Interactions Between Macro- and Microorganisms in Marine Sediments. American Geophysical Union, Washington, DC, pp. 125-157.

Kriventseva, E.V., Zdobnov, E.M., Simão, F.A., loannidis, P., Waterhouse, R.M., 2015. BUSCO: assessing genome assembly and annotation completeness with single-copy orthologs. Bioinformatics 31, 3210-3212.

Kwon, J.Y., Weon, J.-I., Koedrith, P., Park, K.-S., Kim, I.S., Seo, Y.R., 2013. Identification of molecular candidates and interaction networks via integrative toxicogenomic analysis in a human cell line following low-dose exposure to the carcinogenic metals cadmium and nickel. Oncol. Rep. 30 1185-1194.

Lebioda, L., LaCount, M.W., Zhang, E., Chen, Y.P., Han, K., Whitton, M.M., Lincoln, D.E., Woodin, S.A., 1999. An enzymatic globin from a marine worm. Nature 401, 445.

Li, B., Dewey, C.N., 2011. RSEM: accurate transcript quantification from RNA-Seq data with or without a reference genome. BMC Bioinforma. 12, 323.

Lu, P., Takai, K., Weaver, V.M., Werb, Z., 2011. Extracellular matrix degradation and remodeling in development and disease. Cold Spring Harb. Perspect. Biol. 3, a005058.

Luoma, S.N., Rainbow, P.S., 2008. Metal Contamination in Aquatic Environments: Science and Lateral Management. Cambridge University Press.

Matozzo, V., Gagné, F., Marin, M.G., Ricciardi, F., Blaise, C., 2008. Vitellogenin as a biomarker of exposure to estrogenic compounds in aquatic invertebrates: a review. Environ. Int. 34, 531-545.

McQuillan, J.S., Kille, P., Powell, K., Galloway, T.S., 2014. The regulation of copper stress response genes in the polychaete Nereis diversicolor during prolonged extreme copper contamination. Environ. Sci. Technol. 48, 13085-13092.

Mehr, S., Verdes, A., DeSalle, R., Sparks, J., Pieribone, V., Gruber, D.F., 2015. Transcriptome sequencing and annotation of the polychaete Hermodice carunculata (Annelida, Amphinomidae). BMC Genomics 16, 1-13.

Millero, F.J., Woosley, R., Ditrolio, B., Waters, J., 2009. Effect of ocean acidification on the speciation of metals in seawater. Oceanography $22,72-$ 85 .

Moreno-Hagelsieb, G., Latimer, K., 2007. Choosing BLAST options for better detection of orthologs as reciprocal best hits. Bioinformatics 24,319 324

Mouneyrac, C., Mastain, O., Amiard, J.C., Amiard-Triquet, C., Beaunier, P., Jeantet, A.- Y., Smith, B.D., Rainbow, P.S., 2003. Trace-metal detoxification and tolerance of the estuarine worm Hediste diversicolor chronically exposed in their environment. Mar. Biol. 143, 731-744.

Nakamura, A., Yasuda, K., Adachi, H., Sakurai, Y., Ishii, N., Goto, S., 1999. Vitellogenin-6 is a major carbonylated protein in aged nematode, Caenorhabditis elegans. Biochem. Biophys. Res. Commun. 264, 580-583.

Narimatsu, T., Ozawa, Y., Miyake, S., Kubota, S., Hirasawa, M., Nagai, N., Shimmura, S., Tsubota, K., 2013. Disruption of cell-cell junctions and induction of pathological cytokines in the retinal pigment epithelium of light-exposed mice. Invest. Ophthalmol. Vis. Sci. 54, $4555-4562$.

Neave, M.J., Streten-Joyce, C., Nouwens, A.S., Glasby, C.J., McGuinness, K.A., Parry, D. L., Gibb, K.S., 2012. The transcriptome and proteome are altered in marine polychaetes (Annelida) exposed to elevated metal levels. J. Proteome 75, 2721-2735.

Nielsen, A.M., Eriksen, N.T., Iversen, J.L., Riisgård, H.U., 1995. Feeding, growth and respiration in the polychaetes Nereis diversicolor (facultative filter-feeder) and N. virens (omnivorous)-a comparative study. Mar. Ecol. Prog. Ser. 125, 149-158.

Novo, M., Lahive, E., Díez-Ortiz, M., Matzke, M., Morgan, A.J., Spurgeon, D.J., Svendsen, C., Kille, P., 2015. Different routes, same pathways: molecular mechanisms under silver ion and nanoparticle exposures in the soil sentinel Eisenia fetida. Environ. Pollut. 205, 385-393.

Owen, J., Hedley, B.A., Svendsen, C., Wren, J., Jonker, M.J., Hankard, P.K., Lister, L.J., Stürzenbaum, S.R., Morgan, A.J., Spurgeon, D.J., 2008. Transcriptome profiling of developmental and xenobiotic responses in a keystone soil animal, the oligochaete annelid Lumbricus rubellus. BMC Genomics 9, 266

Özbek, S., Balasubramanian, P.G., Chiquet-Ehrismann, R., Tucker, R.P., Adams, J.C., 2010. The evolution of extracellular matrix. Mol. Biol. Cell 21, 4300-4305. Page-McCaw, A., 2008. Remodeling the model organism: matrix metalloproteinase functions in invertebrates. Semin. Cell Dev. Biol. 1423. Elsevier.

Pan, K., Wang, W.-X., 2012. Trace metal contamination in estuarine and coastal environments in China. Sci. Total Environ. $421,3-16$.

Pini, J., 2014. An Assessment of the Impacts of Chronic Exposure of Copper and Zinc on the Polychaete Nereis (Alitta) virens Using an Integrated Ecotoxicological Approach. University of Portsmouth.

Pomaznoy, M., Ha, B., Peters, B., 2018. GOnet: a tool for interactive Gene Ontology analysis. BMC Bioinforma. 19, 470.

Rainbow, P., Smith, B., Luoma, S., 2009. Differences in trace metal bioaccumulation kinetics among populations of the polychaete Nereis diversicolor from metal-contaminated estuaries. Mar. Ecol. Prog. Ser. 376, 173-184. 
Rainbow, P., Kriefman, S., Smith, B., Luoma, S., 2011. Have the bioavailabilities of trace metals to a suite of biomonitors changed over three decades in SW England estuaries historically affected by mining? Sci. Total Environ. 409, 1589-1602.

Reid, N.M., Proestou, D.A., Clark, B.W., Warren, W.C., Colbourne, J.K., Shaw, J.R., Karchner, S.I., Hahn, M.E., Nacci, D., Oleksiak, M.F., Crawford, D.L., Whitehead, A., 2016. The genomic landscape of rapid repeated evolutionary adaptation to toxic pollution in wild fish. Science 354, 1305-1308.

Reish, D.J., Gerlinger, T.V., 1997. A review of the toxicological studies with polychaetous annelids. Bull. Mar. Sci. 60, 584-607.

Rhee, J.S., Lee, Y.M., Hwang, D.S., Lee, K.W., Kim, I.C., Shin, K.H., Raisuddin, S., Lee, J. S., 2007a. Molecular cloning and characterization of omega class glutathione S- transferase (GST-O) from the polychaete Neanthes succinea: biochemical comparison with theta class glutathione S-transferase (GST-T). Comp. Biochem. Physiol. C Toxicol. Pharmacol. 146, 471-477.

Rhee, J.S., Lee, Y.M., Hwang, D.S., Won, E.J., Raisuddin, S., Shin, K.H., Lee, J.S., 2007b. Molecular cloning, expression, biochemical characteristics, and biomarker potential of theta class glutathione S-transferase (GST-T) from the polychaete Neanthes succinea. Aquat. Toxicol. 83, $104-115$.

Rhee, J.S., Won, E.J., Kim, R.O., Choi, B.S., Choi, I.Y., Park, G.S., Shin, K.H., Lee, Y.M., Lee, J.S., 2012. The polychaete, Perinereis nuntia ESTs and its use to uncover potential biomarker genes for molecular ecotoxicological studies. Environ. Res. 112, 48-57.

Robertson, L.S., Galbraith, H.S., Iwanowicz, D., Blakeslee, C.J., Cornman, R.S., 2017. RNA sequencing analysis of transcriptional change in the freshwater mussel Elliptio complanata after environmentally relevant sodium chloride exposure. Environ. Toxicol. Chem. 36, 2352-2366.

Robinson, M.D., McCarthy, D.J., Smyth, G.K., 2010. edgeR: a Bioconductor package for differential expression analysis of digital gene expression data. Bioinformatics 26, 139-140.

Rosenzweig, A.C., Huffman, D.L., Hou, M.Y., Wernimont, A.K., Pufahl, R.A., O’Halloran, T.V., 1999. Crystal structure of the Atx1 metallochaperone protein at $1.02 \AA ̊$ resolution. Structure 7, 605-617.

Rousset, V., Pleijel, F., Rouse, G.W., Ers'eus, C., Siddall, M.E., 2007. A molecular phylogeny of annelids. Cladistics 23, 41-63.

Rozen, S., Skaletsky, H., 1999. Primer3 on the WWW for general users and for biologist programmers. In: Misener, S., Krawetz, S.A. (Eds.), Bioinformatics Methods and Protocols. Humana Press, Totowa, NJ, pp. 365-386.

Sakai, J., Li, J., Subramanian, K.K., Mondal, S., Bajrami, B., Hattori, H., Jia, Y., Dickinson, B.C., Zhong, J., Ye, K., 2012. Reactive oxygen species-induced actin glutathionylation controls actin dynamics in neutrophils. Immunity 37, 1037-1049.

Santos, C.S.G., Pleijel, F., Lana, P., Rouse, G.W., 2006. Phylogenetic relationships within Nereididae (Annelida:Phyllodocida). Invertebr. Syst. 19, $557-576$.

Schirmer, K., Fischer, B.B., Madureira, D.J., Pillai, S., 2010. Transcriptomics in ecotoxicology. Anal. Bioanal. Chem. 397, 917-923.

Seehuus, S.-C., Norberg, K., Gimsa, U., Krekling, T., Amdam, G.V., 2006. Reproductive protein protects functionally sterile honey bee workers from oxidative stress. Proc. Natl. Acad. Sci. U. S. A. 103, 962-967.

Sharpley, M.S., Hirst, J., 2006. The inhibition of mitochondrial complex I (NADH: ubiquinone oxidoreductase) by $\mathrm{Zn}^{2+}$. J. Biol. Chem. 281, 3480334809.

Shneyer, B.I., U`saj, M., Henn, A., 2016. Myo19 is an outer mitochondrial membrane motor and effector of starvation-induced filopodia. J. Cell Sci. 129, 543-556. Short, S., Yang, G., Guler, Y., Green Etxabe, A., Kille, P., Ford, A.T., 2014. Crustacean intersexuality is feminization without demasculinization: implications for environmental toxicology. Environ. Sci. Technol. 48, 13520-13529.

Silver, N., Best, S., Jiang, J., Thein, S.L., 2006. Selection of housekeeping genes for gene expression studies in human reticulocytes using real-time PCR. BMC Mol. Biol. 7, 33.

Simpson, S., Batley, G., Chariton, A., 2007. Revision of the ANZECC/ARMCANZ Sediment Quality Guidelines.

Siwik, D.A., Pagano, P.J., Colucci, W.S., 2001. Oxidative stress regulates collagen synthesis and matrix metalloproteinase activity in cardiac fibroblasts. Am. J. Phys. Cell Phys. 280, C53-C60.

Srinivasan, M., Swain, G.W., 2007. Managing the use of copper-based antifouling paints. Environ. Manag. 39, $423-441$.

Sun, C., Zhang, S., 2015. Immune-relevant and antioxidant activities of vitellogenin and yolk proteins in fish. Nutrients 7, 8818-8829.

Supek, F., Bo`snjak, M., Škunca, N., Šmuc, T., 2011. REVIGO summarizes and visualizes long lists of gene ontology terms. PLoS One 6.

Svingen, T., Letting, H., Hadrup, N., Hass, U., Vinggaard, A.M., 2015. Selection of reference genes for quantitative RT-PCR (RT-qPCR) analysis of rat tissues under physiological and toxicological conditions. PeerJ 3, e855.

Tait, S.W., Green, D.R., 2012. Mitochondria and cell signalling. J. Cell Sci. 125, 807-815. Thomas, P.D., Campbell, M.J., Kejariwal, A., Mi, H., Karlak, B., Daverman, R., Diemer, K., Muruganujan, A., Narechania, A., 2003. PANTHER: a library of protein families and subfamilies indexed by function. Genome Res. 13, 2129-2141.

Thurmond, J., Goodman, J.L., Strelets, V.B., Attrill, H., Gramates, L.S., Marygold, S.J., Matthews, B.B., Millburn, G., Antonazzo, G., Trovisco, V., Kaufman, T.C., 2019. FlyBase 2.0: the next generation. Nucleic Acids Res. 47, D759-D765.

U.S.EPA, 2005. Procedures for the Derivation of Equilibrium Partitioning Sediment Benchmarks (ESBs) for the Protection of Benthic Organisms: Metal Mixtures (Cadmium, Copper, Lead, Nickel, Silver and Zinc)'. EPA-600-R-02-011. Office of Research and Development, Washington, DC, 20460. 
van der Vliet, A., Danyal, K., Heppner, D.E., 2018. Dual oxidase: a novel therapeutic target in allergic disease. Br. J. Pharmacol. 175, $1401-1418$.

Walker, C.H., Sibly, R., Hopkin, S.P., Peakall, D.B., 2005. Principles of Ecotoxicology. CRC press.

Watson, G.J., Pini, J.M., Richir, J., 2018. Chronic exposure to copper and zinc induces DNA damage in the polychaete Alitta virens and the implications for future toxicity of coastal sites. Environ. Pollut. 243, 1498-1508.

Weber, R.E., 1978. Respiratory Pigments, Physiology of Annelids. Academic Press, pp. 393-446.

Wilson, C., Gonz'alez-Billault, C., 2015. Regulation of cytoskeletal dynamics by redox signaling and oxidative stress: implications for neuronal development and trafficking. Front. Cell. Neurosci. 9, 381.

Wippler, J., Kleiner, M., Lott, C., Gruhl, A., Abraham, P.E., Giannone, R.J., Young, J.C., Hettich, R.L., Dubilier, N., 2016. Transcriptomic and proteomic insights into innate immunity and adaptations to a symbiotic lifestyle in the gutless marine worm Olavius algarvensis. BMC Genomics $17,942$.

Wolyniec, K., Levav-Cohen, Y., Jiang, Y., Haupt, S., Haupt, Y., 2013. The E6AP E3 ubiquitin ligase regulates the cellular response to oxidative stress. Oncogene 32, 3510-3519.

Won, E.-J., Kim, R.-O., Rhee, J.-S., Park, G.S., Lee, J., Shin, K.-H., Lee, Y.-M., Lee, J.-S., 2011. Response of glutathione S-transferase (GST) genes to cadmium exposure in the marine pollution indicator worm, Perinereis nuntia. Comp. Biochem. Physiol. C Toxicol. Pharmacol. 154, 82-92. 